\title{
PENGARUH VARIASI TEMPERATUR AIR SEBAGAI PENDINGINAN TERHADAP KARAKTERISTIK CORAN ALUMINIUM DENGAN MEDIA CETAKAN PASIR $\mathrm{CO}_{2}$
}

\author{
Masyrukan \\ Jurusan Teknik Mesin Universitas Muhammadiyah Surakarta \\ Jl.A.Yani Tromol Pos 1 Pabelan, Kartasura \\ Email:masyrukan@gmail.com
}

\begin{abstract}
ABSTRAK
Logam akan mengalami perubahan fasa selama proses pengecoran, baik perubahan sifat fisis maupun mekanik yang disebabkan oleh proses pembekuan. Perubahan sifat ini antara lain dipengaruhi media pendingin yang digunakan pada saat proses pendinginan. Tujuan penelitian ini adalah untuk membandingkan variasi temperatur pendinginan terhadap kekerasan hasil coran aluminium karena sifat fisis dan mekanis suatu logam sangat penting dalam kontruksi permesinan. Maka dalam penelitian ini digunakan media pendinginan yang berbeda yaitu : Air dengan suhu $15^{\circ} \mathrm{C}$, Air dengan suhu $27^{\circ} \mathrm{C}$ dan Air dengan suhu $55^{\circ} \mathrm{C}$. Dari pengujian kekerasan benda uji dengan media pendinginan air suhu $15^{\circ} \mathrm{C}$ mempunyai nilai kekerasan yang lebih baik dibanding air dengan suhu $27^{\circ} \mathrm{C}$ dan $55^{\circ} \mathrm{C}$. Dari hasil pengujian komposisi kimia terdapat 17 unsur, tetapi hanya 4 unsur yang paling berpengaruh pada aluminium cor yaitu $\mathrm{Si}, \mathrm{Fe}$, $\mathrm{Cu}$, dan $\mathrm{Zn}$ yang paling dominan. Dilihat dari unsur yang ada pada material ini dapat digolongkan logam aluminium paduan seng (Al-Zn).
\end{abstract}

Kata kunci: Aluminium (Al), Pendinginan cepat, kekerasan, struktur mikro, komposisi kimia.

\section{PENDAHULUAN}

Pengecoran merupakan proses pembentukan logam dengan cara dicairkan, lalu kemudian dituang kedalam cetakan dan dibiarkan sampai membeku. Bahan yang dipakai dalam cetakan sangat bervariasi, bebrapa contoh diantaranya dibuat dari bahan logam, pasir, semen, kulit, keramik, dan sebagainya. Masing-masing bahan cetakan ini akan memberikan pengaruh terhadap kualitas hasil produk coran logam cair. Kualitas ini terutama mengenai sifat mekanis dan cacat yang terbentuk selama proses penuangan hingga menjadi membeku. Setiap logam akan mengalami perubahan fasa saat proses pengecoran baik sifat fisiknya maupun sifat mekanisnya dan salah satu faktor yang mempengaruhi perubahan fasa adalah proses pendinginan yang salah satunya dipengaruhi oleh faktor temperatur dan media pendinginan.

Berdasarkan uraian di atas maka perlu dilakukan penelitian tentang pengaruh variasi temperatur air sebagai pendinginan terhadap flange coran aluminium dengan media cetakan pasir $\mathrm{CO}_{2}$

\section{TINJAUAN PUSTAKA}

Supriyanto, 2009 meneliti bahwa hasil uji keras pada produk cor aluminium yang menggunakan cetakan pasir menunjukkan bahwa angka kekerasan yang paling tinggi adalah Dari hasil pengujian ketangguhan benda uji dengan media pendinginan udara suhu kamar 
lebih tangguh dibandingkan dengan benda uji dengan media pendinginan oli SAE 40. Hal ini dikarenakan laju pendinginan udara suhu kamar lebih lambat dibanding laju pendinginan oli SAE 40 dan air sumur, struktur mikro benda uji pendinginan udara suhu kamar unsur magnesium $(\mathrm{Mg})$ yang terbentuk lebih banyak dan merata dari benda uji pendinginan oli SAE 40 dan air sumur.

Yuli Cahyo Pamungkas dkk, 2016 Pengaruh quenching menggunakan air-oli SAE 40 dengan perbandingan 10\%-90\% lama pencelupan 5 menit, 10 menit, 15 menit terhadap kekerasan $\mathrm{Al}-\mathrm{Si}$, mengindikasikan, bahwa lama pencelupan dalam proses quenching yang menggunakan campuran media pendingin 90\% air dan 10\% oli Mesran SAE 40 berpengaruh terhadap tingkat kekerasan paduan Al-Si. Pengaruh tersebut tampak dari kecenderungan tingkat kekerasan yang meningkat, yakni 57,54 HV untuk lama pencelupan 5 menit, 58,01 HV untuk lama pencelupan 10 menit, dan 58,15 HV untuk lama pencelupan 15 menit.

Elin Nuraini dkk,1996 Pengaruh media pendingin udara, pasir, dan air memberikan perbedaan kekerasan dan ukuran butir AlMg2 yang mengalami perlakuan panas pada suhu $200^{\circ} \mathrm{C}$ selama 6 jam. Dengan pendingin air diperoleh kekerasan tertinggi yaitu $59 \mathrm{~kg} / \mathrm{mm}^{2}$ dan terendah adalah dengan pendingin pasir diperoleh $57,5 \mathrm{~kg} / \mathrm{mm}^{2}$, sedangkan dengan pendingin udara diperoleh $58,7 \mathrm{~kg} / \mathrm{mm}^{2}$. Ukuran butir yang diperoleh adalah $26,8 \mu \mathrm{m}, 27,3 \mu \mathrm{m}$ dan 27,0 $\mu \mathrm{m}$.

\section{METODE PENELITIAN}

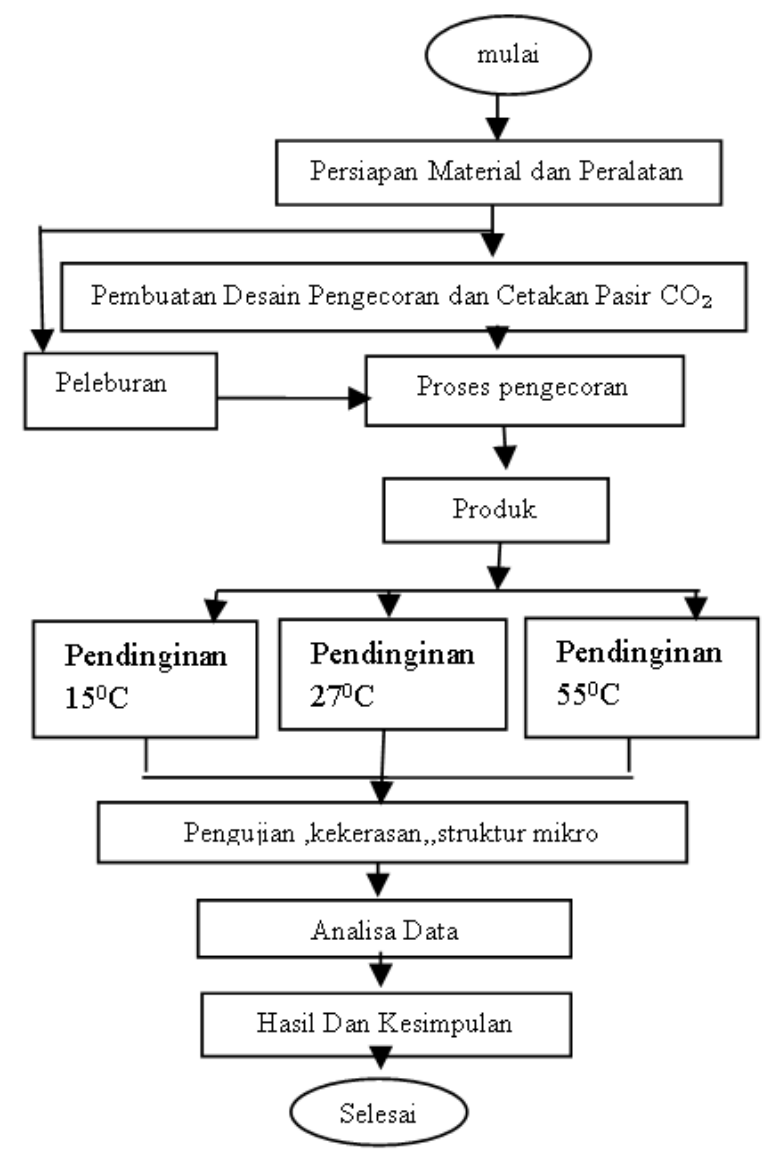

Gambar 1. Diagram Alir Penelitian 


\section{Bahan dan Alat Penelitian}

\section{A. Bahan}

Bahan yang digunakan dalam penelitian ini :

1. Aluminium bekas atau rosok yang berasal dari sparepart pabrik dan berbagai bahan campuran logam aluminium.

2. Kalsium karbonat (bubuk anti air)

3. Pasir silika

4. Water glass

5. Air suhu $15^{\circ} \mathrm{C}$

6. Air suhu $27^{\circ} \mathrm{C}$

7. Air suhu $55^{\circ} \mathrm{C}$

\section{B. Alat}

Peralatan yang dipergunakan dalam penelitian ini antara lain;

Cangkul, Kowi, Tali pengikat cetakan $\mathrm{CO}_{2}$,Penumbuk, Gayung, Tabung silinder ,Mesin. pengaduk, Digital Caliper, Lanset, Ember, Alat uji Spektrometer, Gancu Kerangka cetakan, Alat uji Kekerasan HRB, Ladel, Tabung Gas $\mathrm{CO}_{2}$, Alat uji Mikroskop Metalografi, Saringan (pengayak), Gergaji besi, Dapur pelebur dan Linggis

\section{Prosedur Penelitian}

\section{Pembuatan Cetakan}

1. Mempersiapkan kerangka cetakan berbentuk kotak

2. Mempersiapkan papan kayu diletakkan bagian bawah sebagai alas kerangka cetak bawah.

3. Meletakan kerangka cetakan diatas papan kayu dan meletakkan pola flange diatas papan kayu.

4. Mencampurkan pasir silika dan cairan water glass secukupnya kemudian diaduk hingga tercampur merata dan sedikit mengeras \pm 1 menit .

5. Mengisi pasir silika yang sudah tercampur dan diaduk dengan cairan water glass sampai batas permukaan kerangka cetakan, kemudian dipadatkan menggunakan penumbuk hingga padat merata setelah itu bagian atas kerangka cetakan diletakkan papan kayu kemudian dibalik berada dibawah dan bagian bawah pola flange berada diatas .

6. Mengambil papan kayu yang berada diatas dan meratakan pasir yang berada dipermukaan apabila masih terdapat pasir yang belum merata sempurna menggunakan sendok.

7. Melapisi bagian atas cetakan menggunakan kantong kresek agar pada saat melakukan proses memberi gas co pada pasir tidak menembus ke bagian bawah cetakan, setelah itu memasang lagi kerangka cetakan dan meletakan tabung silinder berukuran $\pm 1 \mathrm{~cm}$ yang berfungsi sebagai saluran turun sprue dan mengisi pasir yang tercampur water glass tersebut ke dalam cetakan bagian atas yang sudah dilapisi dengan kantong kresek hingga menutupi permukaan kerangka cetakan dan kemudian ratakan.

8. Kemudian mencabut tabung silinder tadi dan terbentuklah saluran turun sprue setelah itu membuat saluran udara pada bagian tengah menggunakan tabung silinder berukuran $\pm 1 \mathrm{~cm}$ pada cetakan guna membuang gas - gas pada saat penuangan cairan coran. 
9. Kemudian membuat saluran masuk gas $\mathrm{CO}_{2}$ menggunakan tabung silinder berukuran $\pm 0,5 \mathrm{~mm}$ sebanyak 3 titik masing - masing pada bagian samping kanan dan kiri dan 3 titik pada bagian tengah.

10. Setelah itu memberikan gas $\mathrm{CO}_{2}$ dengan tekanan $\pm 1-1,5 \mathrm{~N} / \mathrm{m}^{2}$ kedalam saluran gas $\mathrm{CO}_{2}$ yang sudah dibuat sebelumnya hingga mengeras dengan waktu \pm 1 menit.

11. Mengangkat cetakan bagian atas, kemudian mengambil pola flange dengan cara menancapkan paku ke pol kemudian diketuk perlahan - lahan agar pola bergeser setelah itu diambil pola tersebut secara perlahan sehingga cetakan pasir $\mathrm{CO}_{2}$ tidak runtuh, setelah itu meratakan bagian yang belum rata.

12. Kemudian membuat saluran masuk gas $\mathrm{CO}_{2}$ menggunakan tabung silinder berukuran $\pm 0,5 \mathrm{~cm}$ pada cetakan bawah pada 3 titik masing - masing bagian pojok dan 2 titik pada bagian tengah.

13. Membuat saluran masuk ingate pada pola atas posisikan dipojok dan dipresisikan dengan lubang dari saluran turun sprue, setelah itu memberikan gas $\mathrm{CO}_{2}$ dengan tekanan $\pm 1-1,5 \mathrm{~N} / \mathrm{m}^{2}$ kedalam saluran gas $\mathrm{CO}_{2}$ yang sudah dibuat sebelumnya hingga mengeras dengan waktu \pm 1 menit, kemudian memasang kembali cetakan atas dan dipresisikan antara lubang saluran turun (sprue) dan saluran masuk (ingate)

\section{Proses Pengecoran}

Pada proses pengecoran ini adalah meleburkan bahan alumunium dalam tungku,kemudian setelah alumunium benar benar cair ,cairan alumunium ini di ambil dari tungku peleburan dengan ladeldan dituangkandalam cetakan yang telah disiapkan

\section{Proses Pendinginan}

Pendinginan dengan variasi 3 media yaitu air suhu $15^{\circ} \mathrm{C}$, air suhu $27^{\circ} \mathrm{C}$ dan air suhu $55^{\circ} \mathrm{C}$.Prosesnya adalah setelah Aluminium (Al) cair di tuangkan dari ledel ke dalam lubang saluran masuk cetakan Pasir $\mathrm{CO}_{2}$ dan didiamkan 10 menit setelah dirasa sudah mengeras lalu cetakan dibongkar dan spesimen dimasukan ke dalam 3 media pendinginan tersebut, sistem pendinginan dalam pengecoran aluminium (Al) menggunakan beberapa media pendingin dan lama pendinginan 1 jam.

\section{Pengamatan Porositas}

Pada pengamatan porositas ini dilakukan dengan cara memotong sebagian spesimen dengan secara acak. Kemudian pada bagian potongan tersebut dilakukan mounting dengan menggunakan resin dan katalis yang kemudian diamplas sampai halus dan diberi autosol supaya porositas dapat terlihat jelas dan setelah itu difoto makro menggunakan kamera dan dilakukan perbandingan dari setiap variasi pendingin

\section{Pengujian Kekerasan}

Kekerasan merupakan ketahanan bahan terhadap goresan atau penetrasi pada permukaannya. Pengujian ini dilakukan untuk mengetahui hasil kekerasan dari benda uji pada bebrapa bagian sehingga diketahui distribusi kekerasan rata-ratanya dari semua bagian yang diuji.

\section{HASIL DAN PEMBAHASAN}

\section{Pengujian Kekerasan Hasil Produk Cor Aluminium}

Pengujian kekerasan menggunakan HRв (Hardness Rockwell Ball type B) dengan beban $981 \mathrm{~N}$ (100,034 Kgf ) menggunakan penetrator bola diameter 1/16 in.dilakukan pada 5 titik pada bagian spesimen. 


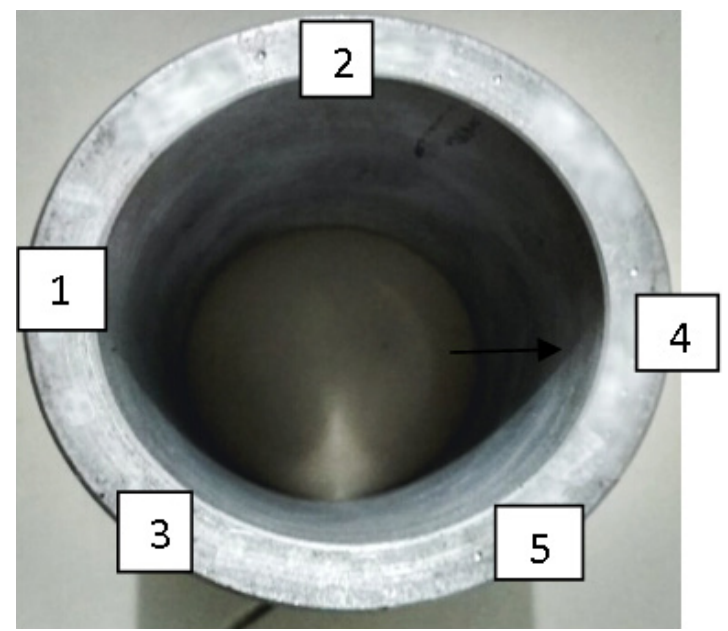

Gambar 2. Posisi Titik Kekerasan Spesimen.

\section{Harga Kekerasan HRв (Hardness Rockwell Ball type B)}

Harga kekerasanHRв (Hardness Rockwell Ball type B) variasi pendinginan air suhu $15^{\circ} \mathrm{C}$,air suhu $27^{\circ} \mathrm{C}$ dan air suhu $55^{\circ} \mathrm{C}$ terhadap hasil produk aluminium cor dapat dilihat seperti pada table 1

Tabel 1. Hasil Pengujian Kekerasan HRB.

\begin{tabular}{cccccccc}
\hline NO & $\begin{array}{c}\text { Media } \\
\text { Pendinginan }\end{array}$ & \multicolumn{4}{c}{ Kekerasan HRB } & $\begin{array}{c}\text { Rata-rata } \\
\text { HRB }\end{array}$ \\
\hline 1 & Suhu $15^{\circ} \mathrm{C}$ & 30,77 & 29,25 & 29,90 & 30,29 & 29,97 & $\mathbf{3 0 , 0 4}$ \\
2 & Suhu $27^{\circ} \mathrm{C}$ & 20,71 & 20,87 & 19,45 & 19,40 & 19,80 & $\mathbf{2 0 , 0 5}$ \\
3 & Suhu $55^{\circ} \mathrm{C}$ & 16,67 & 15,76 & 15,00 & 15,31 & 15,24 & $\mathbf{1 5 , 6 0}$ \\
\hline
\end{tabular}

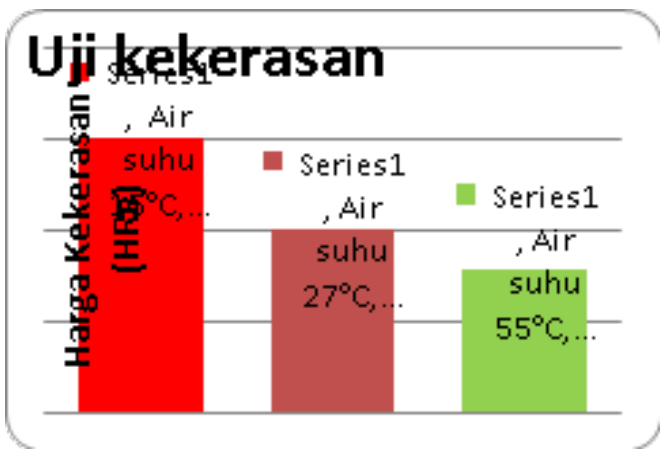

Gambar 3. Grafik hubungan kekerasan dengan variasi pendinginan

\section{Pembahasan Pengujian Kekerasan}

Dari Hasil pengujian kekerasan benda uji dengan media pendinginan suhu $15^{\circ} \mathrm{C}$ lebih keras yaitu 30,04 di bandingkan dengan hasil dari media pendinginan suhu $27^{\circ} \mathrm{C}$ yaitu 20,05 dan media pendinginan suhu $55^{\circ} \mathrm{C}$ yang bernilai 15,6 . Laju dari pendinginan menggunakan media pendingin suhu $15^{\circ} \mathrm{C}$ lebih cepat dibandingkan dengan yang lain, oleh karena itu hasil kekerasannya juga lebih baik. 


\section{Pengamatan Porositas}

Hasil pengamatan porositas dapat dilihat pada poto makro pada gambar 4a,4b dan4c

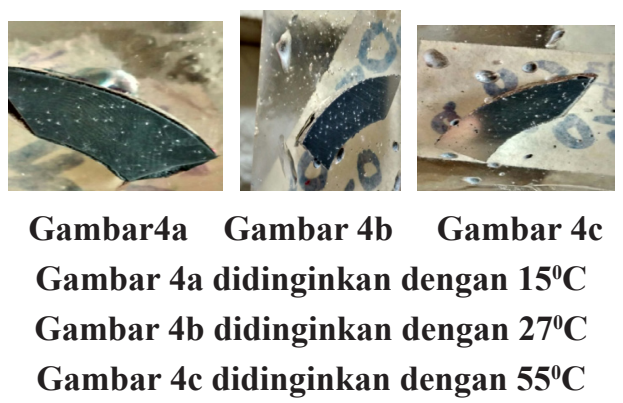

Dari gambar 4a,Gambar 4c dan Gambar 4b,terlihat jumlah porositas (Titik berwarna putih) berbeda dan dihitung dengan luasan yang sama, dan dapat dilihat pada table.2.

Tabel 2. Hasil Pengamatan Porositas

\begin{tabular}{|c|c|c|}
\hline $\begin{array}{c}\text { Variasi } \\
\text { Pendinginan }\end{array}$ & & jumlah porositas \\
\hline Air suhu $15^{\circ} \mathrm{C}$ & & 35 \\
\hline Air suhu $27^{\circ} \mathrm{C}$ & & 42 \\
\hline Air suhu $55^{\circ} \mathrm{C}$ & & 47 \\
\hline 35 & 42 & 47 \\
\hline $\begin{array}{c}\text { Air suhu } \\
15^{\circ} \mathrm{C}\end{array}$ & $\begin{array}{c}\text { Air suhu } \\
27^{\circ} \mathrm{C}\end{array}$ & $\begin{array}{l}\text { Air suhu } \\
55^{\circ} \mathrm{C}\end{array}$ \\
\hline
\end{tabular}

Gambar 5. Grafik hasil pengamatan porositas

\section{Pembahasan Pengamatan Cacat Porositas}

Berdasarkan hasil dari foto makro kamera diatas (gambar 4) dapat dilihat bahwa hasil produk yang menggunakan variasi pendinginan suhu $15^{\circ} \mathrm{C}$ memiliki tingkat porositas yang lebih sedikit atau rendah dibandingkan dengan variasi pendinginan suhu $27^{\circ} \mathrm{C}$ dan variasi pendinginan suhu $55^{\circ} \mathrm{C}$. Sedangkan pada variasi pendinginan suhu $27^{\circ} \mathrm{C}$ dan variasi pendinginan suhu $55^{\circ} \mathrm{C}$. kedua-duanya memiliki tingkat cacat porositas yang lebih banyak jika dibandingkan dengan variasi pendinginan suhu $15^{\circ} \mathrm{C}$. Ada beberapa penyebab terjadinya Cacat porositas salah satu nya adalah sebagai berikut:

1. terjadi akibat udara yang terperangkap didalam cetakan pada penuangan dan dari gas hidrogen yang terlarut dalam cairan logam yang kemudian dilepaskan selama proses pembekuan.

2. Atom-atom pengikat cetakan yang bersentuhan dengan logam cair akan terurai dan membentuk gas-gas yang akan masuk kedalam logam cair dalam bentuk glembungglembung. 
3. Zat -zat organik yang terkandung didalam pasir dan kotoran yang menempel pada aluminium rosok ketika pada proses peleburan.

Keberadaan porositas akan mempengaruhi tingkat kekerasan dari suatu produk cor, semakin banyak cacat porositas pada suatu benda/produk maka tingkat kekerasan akan menurun begitu juga dengan sebaliknya. Maka produk ini semakin tidak aman untuk dijadikan bahan untuk membuat komponen yang bergerak

\section{KESIMPULAN}

1. Dari Hasil pengujian kekerasan benda uji dengan media pendinginan suhu $15^{\circ} \mathrm{C}$ lebih keras yaitu 30,04 di bandingkan dengan hasil dari media pendinginan suhu $27^{\circ} \mathrm{C}$ yaitu 20,05 dan media pendinginan suhu $55^{\circ} \mathrm{C}$ yaitu 15,60 . Laju dari pendinginan suhu $15^{\circ} \mathrm{C}$ lebih cepat dari laju pendinginan suhu $27^{\circ} \mathrm{C}$ dan pendinginan suhu $55^{\circ} \mathrm{C}$ sehingga membuktikan bahwa semakin cepat laju pendinginan maka semakin baik hasil kekerasannya.

2. Dari Pengamatan jumlah porositas dengan media pendingin suhu $15^{\circ} \mathrm{C}$ lebih sedikit jumlah porositasnya 35 dibandingkan dengan yang bermedia pendingin dengan suhu $27^{\circ} \mathrm{C}$ sebanyak 42 dan pada media pendingin $55^{\circ} \mathrm{C}$ sebanyak 47

\section{DAFTAR PUSTAKA}

[1] Amstead, B.H, dkk. 1996. Teknologi Mekanik, Penerbit Erlangga, Jakarta

[2] Asm. 2004. Introduction to Aluminium - Silicon Casting Alloys, Atlas

[3] Of Microfractographs

[4] Astika, I Made, dkk. 2010. Pengaruh Jenis Pasir Cetak Dengan Zat Pengikat Bentonit Terhadap Sifat Permeabilitas Dan Kekuatan Tekan Basah Cetakan Pasir (Sand Casting), Jurnal Ilmiah Teknik Mesin, Universitas Udayana

[5] Avner, Sidney. 1974. Introduction To Physical Metallurgy, Library Of

[6] Congress Cataloging In Publication Data.

[7] Budiyono, Sidiq, dkk. 2013. Pengaruh Kualitas Pengecoran Pasir Cetak Basah Dengan Campuran Bentonit 3\% dan 5\% Pada Besi Cor Kelabu, Jurnal Ilmiah Teknik Mesin, Universitas Sebelas Maret.

[8] Hananto, Adam, Patna Partono. 2016. Pengaruh Variasi Media Cetakan Pasir, Cetakan Logam dan Cetakan RCS (Resin Coated Sand) terhadap Produk Coran Aluminium, Jurnal Ilmiah Teknik Mesin, Universitas Muhammadyah Surakarta

[9] Surdia, Tata, dkk. 1996. Teknik Pengecoran Logam. Penerbit Pradnya

[10] Paramita, Jakarta 